\title{
TOWARDS A TAXONOMY OF CYBER PHYSICAL SYSTEM APPLICATIONS IN CONSTRUCTION
}

\author{
Nazila Roofigari Esfahan ${ }^{1}$ and Chimay J. Anumba ${ }^{2}$
}

\begin{abstract}
Cyber-physical systems (CPS) facilitate the integration of physical processes through offering embedded computation and communication. Through this embedded communication and computation, CPS has the ability to add more intelligence to physical processes and provides effective means for bidirectional coordination between physical entities and their virtual representations. CPS is still considered to be a nascent technology in many industries including construction, and there are many challenges yet to be addressed. However, there is growing interest in this technology and several applications of CPS in improving various construction processes have been proposed in the last few years. This paper classifies current CPS applications presented in the literature for construction projects and accordingly presents a preliminary taxonomy of CPS applications in Construction. To this end, the different components and methods that are required for the application of CPS in construction are characterized and classified and the areas that require further research are identified. It is expected that this taxonomy and its mapping to relevant systems will be highly useful for further development of CPS for improving construction processes.
\end{abstract}

Keywords: Cyber Physical Systems, Construction, Automation, Computer Integrated Construction, Computer-aided design.

\section{INTRODUCTION}

Cyber-Physical Systems (CPSs) are the next generation of engineered multi-disciplinary and physically-aware systems that integrate embedded computing technology into physical processes by using transformative research approaches (Gunes et al. 2014, Krishna 2015). Such an integration requires constant observation, communication, and control aspects of the physical systems from the multi-disciplinary perspective. In fact, CPS is "a new discipline at the intersection of physical, engineering and information sciences" (Sztipanovits et al. 2012); where embedded computers and networks monitor and control the physical processes. Physical processes in this purpose are compositions of many things occurring at the same time, unlike computational processes, which are deeply rooted in sequential steps (Derler et al. 2012). These processes and computations interact and have impact on each other through feedback loops. In other words, CPS is a reactive system, meaning it is in continual interaction with its environment and executes at a pace determined by that environment (Marwedel 2011).

In recent years, CPS has started to be used in a wide range of application fields; including intelligent transportation, agriculture, healthcare and medical devices, infrastructure monitoring, and aerospace. Despite its slower pace compared to other industries, the construction industry has started to take the first steps in introducing Cyber

\footnotetext{
${ }^{1}$ Post-doctoral Associate, M.E. Rinker, Sr. School of Construction Management, University of Florida, Gainesville, Florida, US, nazila.roofigari@ufl.edu

${ }^{2}$ Professor and Dean, College of Design, Construction and Planning, University of Florida, Gainesville, Florida, US, anumba@ufl.edu
} 
Physical Systems to construction processes. To this end, a number of approaches have been explored with the aim to improve automation and real-time communication in construction projects, although they might not necessarily use the term CPS.

The motivation for this study arises from a lack of unifying concepts, related terminologies, challenges, and applications of CPS in the construction sector. The aim is to provide sufficient insight into CPS concepts and common applications in general, as well as its current and potential applications in the construction industry. Development of a taxonomy has been considered an effective and efficient approach to consolidating knowledge, by displaying the domain in an easy way to understand, communicate, teach, learn, and work with (Reisman 2005). According to Bailey (1994), the basic strategy to develop a taxonomy is to classify empirical entities into homogeneous classes (i.e., taxon) based on their similarity on pre-defined variables. As a result, the current work aims to develop a preliminary taxonomy to consolidate the knowledge of CPS within different phases of construction projects, and provide guidance for better leveraging various approaches to fulfil current and near-term future construction needs. As mentioned earlier, the taxonomy represents cyber-physical systems as an umbrella covering all other similar approaches. As a result, it is expected that current work provide a structuring of current approaches, which also allows for future expansion.

\section{Cyber Physical Systems}

CPS can be seen as the integration of embedded systems, sensors, and control systems. There are a number of technological advancements that are opening the door for CPS improvement. Devices are becoming cheaper as they get smaller and smaller. There are also breakthroughs in wireless communications, Internet bandwidth, and the constant increase in alternative energy sources and energy potential. Computer parts are becoming increasingly high capacity at lower power consumption and smaller form factors.

\subsection{Components of CPS}

A CPS typically includes a network of devices that receive and perform physical actions while simultaneously being controlled and monitored by computational and communication software (Lee 2008). Although CPS is a relatively new concept, the system components are well-known. CPS is composed of the physical world, interfaces, and the cyber systems. The physical world refers to the physical phenomena that need to be monitored or controlled. The cyber systems refer to the embedded computational devices, which process information and communicate with their distributed environment. Interfaces refer to the communication network and other intermediate components, e.g. interconnected sensors, actuators, analog-to-digital converters (ADC), and digital-toanalog converters (DAC), responsible for bridging the cyber systems with the physical world. Sensors and actuators are responsible for converting other forms of energy to electricity (analog signal) and vice versa. ADC and DAC are responsible for converting continuous analog signals to discrete digital signals and vice versa. Some core concepts in CPS can be traced back to the sensor network research and technologies related to sensor nodes and sensor networks. A sensor node integrates sensors, actuators, computing elements (e.g. processor, memory, etc.), communication modules, and a battery. The sensor network interconnects many small sensor nodes via wireless or wired connection. Wireless Sensor Networks (WSN) comprise a large number of sensor nodes equipped with wireless network connection that can be deployed in the environment of the physical 
phenomenon. These sensor nodes may provide raw data to the nodes responsible for data fusion or they may process the raw data by means of their computing capabilities and relay the required part of it to the other sensor nodes.

\subsection{Similar Terminologies}

Integration of physical processes and computing is not new. The term "embedded systems" has been used for some time to describe engineered systems that combine physical processes with computing (Lee 2008). Cyber Physical Systems add to the existing embedded systems through bi-directional interactions that are intensely embedded in physical procedures and components. In this way, new characteristic and possibilities are added to physical components and enable automatic control and computation to be performed in cyberspace. A range of concepts similar to CPS is illustrated in Figure 1 these are sometimes interchangeably used in construction applications (Gunes et al. 2014).

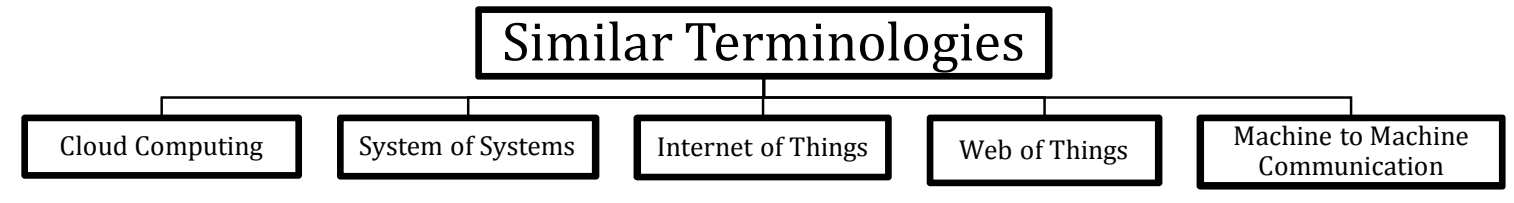

Figure 1: Similar terminologies to CPS

\subsection{Cyber Physical Applications}

Originated from computer science, CPS have been promoted and applied in a number of areas including manufacturing, aerospace, power grids, agriculture, healthcare, and transportation. In the manufacturing industry, CPS has been deployed to help manage dynamic changes in production (e.g. Kaihara and Yao 2012). In the aerospace industry CPS is used for different purposes including automatic pilot avionics, aviation management as well as making intelligent adaptive cyber-physical ecosystem for the aerospace workforce (e.g. Noor 2011). Smart grid technology is being developed using CPS applications in power grids (Krogh et al. 2008, Shi et al. 2011). The healthcare industry is also increasingly relying on CPS for networked medical systems and health information networks as well as medical devices (Kim et al. 2010, Wu et al. 2011). Use of CPS in improving agriculture systems includes data management of production experiments, fundamental geographic information of farmland, micro-climate information and other data (e.g. Zhijun et al. 2003, Agnelo et al. 2010).

The application of CPS in Transportation systems has been more versatile than other industries. Vehicular Cyber Physical Systems (VCPS) refers to a wide range of integrated transportation management systems which should be real-time, efficient and accurate. These applications include but are not limited to promoting the development of intelligent traffic systems, cooperative vehicle safety (CVS), Intelligent Transportation Systems (ITS), connected vehicles, automated vehicles and smart highways (Fallah and Sengupta 2012, Gong and Li 2013). In recent years, there are also discussions about expanding the concepts of intelligent transportation systems into smart cities, where information and communication technologies (ICT) are used to enhance quality and performance of urban services, to reduce costs and resource consumption, and to engage more effectively and actively with its citizens. 


\section{TAXONOMY OF CPS USE IN CONSTRUCTION APPLICATIONS}

Over the last two decades, the construction industry has also moved toward being more automated. The movement started with addressing the main area of concern in the execution of construction projects: progress monitoring and keeping projects on time and budget. It was found that the main reason behind construction projects being over-time and/or over-budget is the fact that there is a gap between project design and actual project execution. To overcome this problem, academics got help from Wireless Sensor Networks and mobile technologies. After different feasibility studies, it was concluded that the successful implementation of mobile technologies, regardless of the initial set-up costs, is a valuable tool to reduce some of the unnecessary costs currently inherent in construction projects (Bowden et al. 2006).

The application of mobile technologies and automatic knowledge and data transfer becomes more versatile in construction projects every day. However, although these approaches are considered as the first steps towards bi-directional automation offered by CPS, still do not satisfy its whole requirements. Proper applications of CPS (or similar terminologies) in construction industry can substantially enhance the control of the construction projects. Current and potential CPS applications in construction industry can be classified based on the life-cycle phase of the project they tend to improve. These phases cover the whole life-cycles of construction projects, from Pre-construction phase to Construction and post-construction phase of the built facility as shown in Figure 2.

\begin{tabular}{|l|l|l|}
\hline Pre-Construction Phase & Construction Phase & Post-Construction Phase \\
\hline Initiation/Feasibility & $\begin{array}{l}\text { Execution } \\
\text { Planning/Design }\end{array}$ & $\begin{array}{l}\text { Operation and } \\
\text { Maintenatnce }\end{array}$ \\
\hline
\end{tabular}

Figure 2: Life-Cycle Construction Phases

Here, the main applications of CPS in construction are classified based on their respective phases as shown in Figure 3.

\begin{tabular}{|c|c|c|c|c|c|c|c|}
\hline & & & $\begin{array}{r}\text { Current CPs } \\
\text { Con }\end{array}$ & $\begin{array}{l}\text { Applications } \\
\text { truction }\end{array}$ & & & \\
\hline & Planning & Construction & & & Operation/ & aintenance & \\
\hline $\begin{array}{c}\text { Progress } \\
\text { Monitoring }\end{array}$ & Safety & \begin{tabular}{|c|} 
Heavy \\
Construction
\end{tabular} & $\begin{array}{l}\text { Temporary } \\
\text { Structure }\end{array}$ & $\begin{array}{c}\text { Facility } \\
\text { Management }\end{array}$ & $\begin{array}{c}\text { Energy } \\
\text { Efficiency }\end{array}$ & $\begin{array}{c}\text { Health } \\
\text { Monitoring }\end{array}$ & $\begin{array}{l}\text { Infrastructure } \\
\text { Management }\end{array}$ \\
\hline
\end{tabular}

Figure 3: Current CPS applications in Construction

\subsection{Pre-construction Phase}

The current CPS applications mainly focus on construction and post-construction phases of the construction projects. The use of CPS in ameliorating the pre-construction phase of construction projects is mainly overlooked. Such applications provide for automation throughout the initiation and feasibility study stages of the project, and result in a more realistic view of the project in hand. The existing planning approaches also focus on the concurrent planning during construction phase and not the pre-construction planning. Subsequently, benefiting from the automation and communication offered by CPS in the design and planning stages ensures constructible designs which reduce the need for change orders in the construction phase. Consequently, more reliable construction plans can be made. To this end, construction projects can greatly benefit from the integration of 
virtual construction models including Augmented Reality (AR) in the pre-construction phase (Khalid et al. 2014). Such an integration would potentially decrease during construction and can accordingly play an important role in on time/budget completion of the projects.

\subsection{Construction Phase}

The first traces of employing automated systems and CPS in the construction industry included improving planning and control of the projects during construction phase. It should be mentioned that planning here accounts for the inherent planning during construction phase of the construction projects. Different processes in this phase can benefit from the advantages of CPS as explained below.

\subsubsection{Progress Monitoring}

Construction projects are typically spread across large uncontrolled outdoor environments and require remote collaboration of multiple resources. Moreover, every construction project is unique, accordingly calling for dissimilar managerial decisions to be made on a daily basis. These characteristics of construction projects create logistical challenges for obtaining a real-time overview of operational status on construction worksites. As a result, the resulting lack of timely insight leads to delayed and sub-optimal decision making based mostly on subjective assumptions and past experiences. The employment of appropriate project performance planning and control techniques plays an important role in the success of construction projects to optimally meet key project performance indicators such as cost, time, and productivity. Such project control systems seek to closely monitor the progress being made on the construction worksite and compare the results with the asplanned work to automatically identify and troubleshoot deviations from the schedule. In order to overcome the lack of on-time information on worksites and to enable timely decision making, real-time performance planning, control and management systems should be put in place to enable real-time monitoring of the projects. Such monitoring can be made in terms of project's main performance indicators; namely schedule, cost and productivity.

\subsubsection{Safety Management}

The construction industry still has the poorest Health and Safety (H\&S) record of any major industry (Naticchia et al. 2013). To improve safety in a construction site, workers and managers need to be aware of activities and elements within the work environment (Oloufa et al. 2003, Hassanzade et al. 2016). The real-time safety management approaches mainly focus on improving workers' situation awareness to prevent safety hazards from happening, or to minimize their negative impact. The real-time awareness and feedback loops offered by CPS has the potential to substantially improve safety management in construction worksites. Such improvements can be made in different stages: Prediction of potential hazards before construction, Prediction and prevention of hazards during construction (before it occur) and minimization of hazard impacts (after occurrence).

\subsubsection{Heavy Construction}

Heavy construction work is a highly equipment-intensive process, and it usually spreads over miles, which makes project planning and control more difficult and exposes contractors to greater schedule and financial risks (Song et al 2009). Successful execution and control of these projects relies on both effective master planning and short-term lookahead plans. Employment of CPS in different phases of heavy construction projects 
improves project performance through real-time dynamic capturing of extensive data from actual operations, analysis and communication of this big data to other operations and participants and updating look-ahead and master plans, and allowing for real-time feedbacks updates from all project participant.

\subsection{Post-Construction Phase}

Owners and project stakeholders are often focused on the initial construction costs of a project. However, the subsequent operation and maintenance of a constructed facility over its life cycle could cost many times more than its initial construction. Although the existing information and management systems for a project's operation/maintenance phase such as computerized maintenance management systems (CMMS), electronic document management systems (EDMS), energy management systems (EMS), and building automation systems (BAS) support management individually, the data is still fragmented (Becerik-Gerber et al. 2011). In addition, the data is entered manually after the hand-over of a building, which is a laborious and inefficient process. As a result, CPS has the potential to improve these processes to be integrated and communicate required data timely and effectively.

\subsubsection{Facility Management}

Although the construction industry is moving towards automation, the FM sector continues to encounter the problem of information management, due to the insufficiency of information and its fragmentation (Parn et al. 2017). There is growing interest in the use of virtual models and visualization in facilities management (FM) for coordinated, consistent, and computable building information/knowledge management during maintenance and operation stages. Such facility management not only includes maintenance management, but also communication, emergency preparedness, environmental sustainability, human factors, quality and property management (Aziz et al. 2016). Such integrated FM requires real-time access to the information regarding all the included components and the ability to communicate their status automatically. The automated and integrated bi-directional monitoring and management support provided by Cyber-Physical Systems has the potential to revolutionize the current FM automation systems and bring required integrity to the FM practices.

\subsubsection{Energy Efficiency}

Whilst aggressive building regulations and standards for new buildings and existing building retrofits are important, there is a need to address substantial energy performance gaps for buildings in use. Integrated Design Processes (IDP) for the delivery of new buildings and retrofits together with Post-Occupancy Evaluation (POE) may offer ways forward (Min et al. 2016). In the meantime, however, further opportunities to reduce energy costs and carbon emissions should not be overlooked. Proactive FM practicing through employment of CPS, as explained above, can significantly reduce the energy performance of the facilities.

\subsubsection{Health Monitoring}

Undetected structural deterioration and extreme loading events are two major causes of structural failures in building systems. Structural health monitoring systems are an objective and quantitative-based management tool that have been developed to assist structure owners with their diagnostic and prognostic decision making processes. In current practice, trained inspectors regularly carry out visual inspections to qualitatively 
evaluate the condition of structures to ensure their safety for public use. While innovative means of storing and exposing structural monitoring data for data processing are presented (e.g. Bocca et al. 2011, Hackmann et al. 2014), these systems often do not store detailed structural information that can be linked to sensor data (Zhang et al. 2016). Ultimately, data-management systems with the capability to comprehensively combine structural information, lifecycle information, and sensor data are required. In addition, the entire process should be made automatic, eliminating the human-factor errors. Proper means of communication should also be enabled to permit flawless real-time data availability. As a result, with its inherent integrated structure, CPS can greatly improve current health monitoring practice.

\subsubsection{Infrastructure Management}

Maintaining reliability and robustness of critical national and international infrastructure is extremely challenging and requires a comprehensive strategy to ensure their safe and proper performance. As a result, civil infrastructure systems such as transportation systems and water and sewer systems also need to be closely monitored. Sensing the current situation of the infrastructure and reasoning about its implication can enhance their real-time system resiliency and responsiveness. Consequently, employment of Cyber Physical Systems in management of civil infrastructures not only ensures their safety and functionality, but also paves the way towards the greater goal of establishing smart cities.

\section{CONCLUDING REMARKS}

Effective integration of CPS into slow-to-change construction processes certainly is not a simple task and a number of challenges and difficulties need to be addressed. There are a few limitations that must first be resolved before the next major step toward CPS advancement can be made. Systems integration is currently the largest obstacle to effective cyber-physical system (CPS) design, which is primarily due to the lack of a solid scientific theoretical foundation (Sztipanovits et al. 2012). Furthermore, designing a system that is highly flexible must be achieved. To this end, CPS must be developed to the point where adjustments and modifications to an already existing system can be made with relative ease. Next, CPS as a whole have not yet progressed beyond the stage of experimentation into a more practical, useful tool in construction practice. The practice, in general, needs to be safe and dependable, as well as accurate enough to operate in real time. Reality modelling and communication is also one the biggest challenges faced in construction practices. Finally, we need to build a CPS that is user friendly. A system that is accessible and easily understood by a wider audience must be achieved in order to promote growth and sustainability

\section{REFERENCES}

Acebes, F., Pajares, J., Galán, J. M. and López-Paredes, A. (2013). Beyond earned value management: A graphical framework for integrated cost, schedule and risk monitoring. Procedia - Social and Behavioral Sciences 74(0): 181-189

Anumba, C., Akanmu, A. and Messner, J. (2010). Towards a cyber-physical systems approach to construction. 2010 Construction Research Congress, Banff, Alberta

Aziz, N. D., Nawawi, A. H., \& Ariff, N. R. M. (2016). ICT Evolution in Facilities Management (FM): Building Information Modelling (BIM) as the Latest Technology. Procedia-Social and Behavioral Sciences, 234, 363-371 
Bailey, K. D. (1994). Typologies and taxonomies: an introduction to classification techniques. Sage. Thosand Oaks, California.

Becerik-Gerber, B., Jazizadeh, F., Li, N. and Calis, G. (2011). Application areas and data requirements for BIM-enabled facilities management. Journal of construction engineering and management, 138(3), 431-442

Bocca, M., Toivola, J., Eriksson, L. M., Hollmén, J. and Koivo, H. (2011) Structural health monitoring in wireless sensor networks by the embedded goertzel algorithm. In Proceedings of the 2011 IEEE/ACM Second International Conference on CyberPhysical Systems, pp. 206-214

Bowden, S., Dorr, A., Thorpe, T. and Anumba, C. (2006). "Mobile ict support for construction process improvement." Automation in Construction 15(5): 664-676

Derler, P., Lee, E. A. and Vincentelli, A. S. (2012). "Modeling cyber physical systems." Proceedings of the IEEE 100(1): 13-28.

El-Omari, S. and Moselhi, O. (2011). "Integrating automated data acquisition technologies for progress reporting of construction projects." Automation in Construction 20(6): 699-705

Fallah, Y. P. and Sengupta, R. (2012). "A cyber-physical systems approach to the design of vehicle safety networks". Distributed Computing Systems Workshops (ICDCSW), IEEE

Gong, D. and Hugsted, R. (1993). "Time-uncertainty analysis in project networks with a new merge-event time-estimation technique." International Journal of Project Management 11(3): 165-173

Gunes, V., Peter, S., Givargis, T. and Vahid, F. (2014). A Survey on Concepts, Applications, and Challenges in Cyber-Physical Systems. TIIS, 8(12), 4242-4268.

Hackmann, G., Guo, W., Yan, G., Sun, Z., Lu, C. and Dyke, S. (2014). Cyber-physical codesign of distributed structural health monitoring with wireless sensor networks. IEEE Transactions on Parallel and Distributed Systems 25, no. 1: 63-72

Hasanzadeh, S., Esmaeili, B. and Dodd, M. D. (2016). Measuring Construction Workers' Real-Time Situation Awareness Using Mobile Eye-Tracking. In Construction Research Congress 2016, pp. 2894-2904

Kaihara, T. and Yao, Y. (2012). A new approach on CPS-based scheduling and WIP control in process industries. In Proceedings of the 2012 Winter Simulation Conference (WSC) pp. 1-11. IEEE

Kim, C., Kim, H., Ryu, J. and Kim, C. (2010). Ubiquitous sensor network for construction material monitoring. Journal of Construction Engineering and Management 137(2): 158-165

Krishna, P. V., Saritha, V. and Sultana, H. P. (2015). Challenges, opportunities, and dimensions of cyber-physical systems, IGI Global

Krogh, B., Lee, E., Lee, I., Mok, A., Rajkumar, R., Sha, L., Vincentelli, A., Shin, K., Stankovic, J. and Lee, E. A. (2007). Computing foundations and practice for cyber-physical systems: A preliminary report. University of California, Berkeley, Tech. Rep. UCB/EECS-2007-72

Marwedel, P., (2010). Embedded System Design, Springer, 2nd Edition.

Min, Z., Morgenstern, P. and Marjanovic-Halburd, L. (2016). Facilities management added value in closing the energy performance gap. International Journal of Sustainable Built Environment, 5(2), 197-209

Naticchia, B., Vaccarini, M., and Carbonari, A. (2013). A monitoring system for real-time interference control on large construction sites. Automation in Construction, 29, 148160 
Noor, A. (2011). Intelligent adaptive cyber-physical ecosystem for aerospace engineering education, training, and accelerated workforce development. Journal of Aerospace Engineering 24(4): 403-408

Oloufa, A. A., Ikeda, M. and Oda, H. (2003). Situational awareness of construction equipment using GPS, wireless and web technologies. Automation in Construction, 12(6), 737-748

Pärn, E. A., Edwards, D. J. and Sing, M. C. P. (2017). The building information modelling trajectory in facilities management: A review. Automation in Construction, 75, 45-55

Reisman, A. (2005). "Transfer of technologies: a cross-disciplinary taxonomy". Omega, 33(3), 189-202.

Shi, J., Wan, J., Yan, H. and Suo, H. (2011). A survey of cyber-physical systems. Wireless Communications and Signal Processing (WCSP), 2011 International Conference on, IEEE.

Song, L., Cooper, C. and Lee, S. (2009). Real-time simulation for look-ahead scheduling of heavy construction projects. Construction Research Congress, pp. 1318-1327

Sztipanovits, J., Koutsoukos, X., Karsai, G., Kottenstette, N., Antsaklis, P., Gupta, V., Goodwine, B., Baras, J. and Wang, S. (2012). Toward a science of cyber-physical system integration. Proceedings of the IEEE 100(1): 29-44

Wu, F.-J., Kao, Y.-F. and Tseng, Y.-C. (2011). From wireless sensor networks towards cyber physical systems. Pervasive and Mobile Computing 7(4): 397-413

Yuan, X., Anumba, C. J. and Parfitt, M. K. (2016). Cyber-physical systems for temporary structure monitoring. Automation in Construction, 66, 1-14

Zhang, Y., O'Connor, S. M., van der Linden, G. W., Prakash, A., and Lynch, J. P. (2016). Senstore: A scalable cyberinfrastructure platform for implementation of data-todecision frameworks for infrastructure health management. Journal of Computing in Civil Engineering, 04016012 